\title{
Development of Physics Lab Assessment Instrument for Senior High School Level
}

\author{
Sarjono \\ Student of Post Graduate Program, Yogyakarta State University, Indonesia, \\ sarjono_mpd@yahoo.com
}

\section{Djemari Mardapi}

Prof., Assessment and Evaluation Education Department, Yogyakarta State University, Indonesia,djemari.@uny.ac.id

\section{Mundilarto}

Prof., Physics Education Department, Yogyakarta State University, Indonesia, mundilarto@uny.ac.id

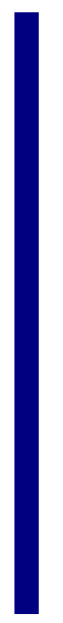

The purpose of this research was to develop a valid, reliable instrument with good difficulty indices for Physics lab test on Senior High School level. By applying research development $(\mathrm{R} \& \mathrm{D})$ design, data were collected through observation, test and project assessment in the form of three categories of polytomous data. The research subject was 505 respondents studying at grade XI-MIA of Public and Private High Schools in Pemalang. The data obtained were analyzed by using three programs, namely Quest program to verify model suitability and difficulty index level, and Parcale program to obtain information function and Standard Error of Measurement (SEM). Confirmatory Factor Analysis using Lisrel program was applied to measure the construct validity of the instrument. Results yielded that the construct of physics lab test instrument at senior high school level consisted of 4 factors, namely (1) preparation of practicum, (2) practicum, (3) practicum results (4) practicum reporting. Developed instruments were valid and reliable, and suitable to be applied to learners who have medium ability. The implications of this study are that the assessment becomes more fair and accurate because assessment is done from the preparation until the lab report.

Keywords: construction, assessment instruments, physics lab, learning, teaching

\section{INTRODUCTION}

Physics lab is important in learning physics. Experiments have been part of the physics education for a very long time. However, in the last two decades their effectiveness as tools for teaching the scientific concepts to the students has been questioned (Havlíček,

Citation: Sarjono, Mardapi, D., \& Mundilarto (2018). Development of Physics Lab Assessment Instrument for Senior High School Level. International Journal of Instruction, 11(4), 17-28. https://doi.org/10.12973/iji.2018.1142a 
2015). Assessment in the learning process is a very important component to measure the achievement of students' learning outcomes, for example, the assessment of scientific work skills (Ariani, et al, 2016).

In addition, Physics is a way of approaching problem solving, which requires direct observation and physical experimentation (AAPT, 2014). An advantage of physics lab usage is that it helps improve learners' higher order learning skills such as analysis, problem solving, and evaluating (Makgato \& Mji, 2006). Assessment plays an important role in education because a qualified assessment system would improve the education quality (Mardapi, 2008). Based on The Assessment Guide by Educators and Education Unit of Senior High School 2017, skill assessment can be conducted through performance assessment by which the teachers do observation (Depdikbud, 2017). In addition, there are four stages in conducting physics lab activity; practicum preparation, practicum performance, practicum results and practicum reporting. Besides, this needs an empirical study to prove whether the construct of practicum assessment consists of four factors as described above. Hence, a physics lab assessment instrument that includes four stages as preserved in the 2013 curriculum is required to develop to be a guide for teachers in developing physics lab instruments. Thus, the purpose of this study is to design a construct of physics lab instrument for physics lab assessment at high school level which is composed of valid and reliable items with good difficulty index level.

\section{REVIEW OF LITERATURE}

\section{Urgency of Physics Lab Assessment}

Education is very important aspect in human life. One of the main efforts to improve the quality of education is to improve the assessment. A commonly advocated best practice for classroom assessment is to make the assessments authentic. Authentic is often used with the meaning of mirroring real-world tasks or expectations. (Frey \& Allen, 2012). The vision of physics education reform that makes students actively engaged in investigating important questions, collecting data, making evidence-based claims, and arguing conclusions requires rather sophisticated subject matter knowledge for physics teachers. (Wenning, 2003). The main skill that must be possessed in the 21 st century curriculum is learning and innovation skill (Chasanah, et al, 2017). The laboratory has been given a central and distinctive role in science education, and science educators have suggested that rich benefits in learning accrue from using laboratory activities. (Hofstein \& Lunetta, 2003). So it is needed to develop instruments for physics practice assessment which covers beginning to end.

Physics is a science generated through observations and experiments conducted by experts who construct laws, principles, concepts, rules in the form of mathematical equations or statements. Physics is a branch of science that is obtained through scientific methods to unravel the mysteries of matter and its interactions with other objects in the universe (Ekawati, 2017). Physics is always related to everyday life, so it is necessary for students to know and understand about physics (Rochmawati \& Wahyuni, 2017). In relation with the notion of science, the following statement of a modern Nobel Prize- 
winning physicist in 1965, Richard Philips Feynman (1963), could be used as a reflection. "The principle of science, the definition, almost is the following: the test of all knowledge is experiment. Experiment is the sole judge of scientific "truth". But what is the source of knowledge? Where do the laws that are to be tested come from? Experiment, itself, helps to produce these laws, in the sense that it gave us hints"

\section{Inquiry-Based Learning}

For learners, learning should shift from being told to actively finding out, in order to construct knowledge for themselves (Depdikbud, 2013). This notion is in line with Piaget's cognitive development theory cited by Orsmond (2004), which affirms that an active child builds or constructs his own knowledge of the world around him as a result of various encounters with the environment, communication with other learners, such as discussion, those could influence his existing schemes or concepts that might lead to rethinking at the starting point of viewpoint.

A child who is learning will experience a series of adjustments to their environments, which are accomplished through two alternative mechanisms, namely the process of assimilation and balanced accommodation through equilibrium. Assimilation is a process of changing the environment to fit into our scheme. New information assimilated by learning can be modified with the concepts that are previously stored in a memory known as accommodation. In relation to the constructivism learning approach, more details can be reviewed in the following Chinn statement (2011). "Constructivism is probably the single most influential theory of learning in contemporary education. Constructivism asserts that learners learn by actively building up ideas on their own. In other words, learners learn by actively thinking about ideas, developing their own interpretations of ideas, and inventing their own ways of understanding about what they are learning. Because each student is unique, learners will construct unique interpretations of what they are studying".

Learners discover in their own way, develop their interpretations in learning to discover the scientific concepts they learn, because each learner has their own uniqueness. Through learning methods that emphasize inquiry, learners usually analyze and evaluate various information to reach decisions or conclusions, learners usually collect or seek some information about themselves. Those processes must be prepared; teachers should plan activities that encourage learners to actively think. A teacher should manage the resources needed and help learners to work actively and effectively.

\section{The Importance of Physics Lab}

Physics lab is an effective learning resource that learners could use to achieve their expected competence. The use of physics lab would likely provide benefits, especially in learning physics learners need to conduct an experimental foundation for the theoretical concepts introduced in the class. Through the practical methods that provide learning experiences to learners, by Physics Lab learners would likely familiarize themselves with experimental apparatus, with various measuring tools, such as calipers, spring balance, thermometer and the usage of practicum materials, such as timer tape paper. Learners need to conduct a series of experiments in order to verify theories, principles 
and laws in physics. In addition, Physics lab allows learners to interact among learners to do a successful experiment. Activities in physics lab would likely improve the conceptual understanding of learners from the relationship of theory-practice, high-level reasoning, skills and development of their practical competence in the laboratory. Through physics lab, learners would interact directly with teachers and fellow learners, both physically and psychologically in a learning environment.

The importance of the physics lab could be reviewed in the following recommendations of the American Association of Physics Teachers (AAPT, 2014). "Physics is a way of approaching problem solving, which requires direct observation and physical experimentation. Being successful in this endeavor requires one to synthesize and use a broad spectrum of knowledge and skills, including mathematical, computational, experimental, and practical skills; and to develop particular habits of mind. "Thinking like a physicist" and constructing the knowledge of our physical universe pervade all of the recommended learning outcomes".

\section{METHOD}

\section{Type of Research}

This study applies a research developed R \& D (Research \& Development) design. The type was chosen because the objective was to develop a learning product (assessment instrument) acquiring fine levels of appropriateness through a process of validation and field testing empirically. The product developed in this research is a physics lab assessment instrument equipped with its rubric and scoring.

\section{Model of Development}

Development of instruments model refers to the development of non-test instruments proposed by Mardapi (2012) that consists of ten steps; 1) determining instrument specifications, 2) writing instruments, 3) determining the scale of instruments, 4) determining scoring scales, 5) reviewing instruments, 6) conducting experimentations, 7) analyzing instruments, 8) assembling instruments, 9) carrying out measurements, and 10) interpreting measurement results. Adaptation is conducted to obtain a model of development that is suitable with the characteristics of the physics lab assessment instrument.

\section{Procedure of Development}

Prior to the instrument development, need analysis was conducted through direct observation of schools by interviewing physics teacher as much as 12 and 20 learners, who are spread across several schools. The purpose of the need analysis is to obtain the real information about the difficulties experienced by the physics teachers in relation to the physics lab assessment instrument. The development procedure in the study includes stages adapted to the developed model. The stages include the pre-development, development, product validation, product revision and evaluation as well as implementation. 
After conducting the need analysis, the next stage is the pre-development stage. This stage includes the determination of test objectives or instruments, and the purpose of the instrument development is for formative tests. The next step is the determining the material tested; the determination of each indicator of the four stages and determining the statement of the indicator. The next step is validating the product by physics education experts and education evaluation experts. In addition to the experts, validation is also conducted by fellow physics teachers. After validation process, revisions and improvement were conducted in accordance with the direction and suggestions of the validators.

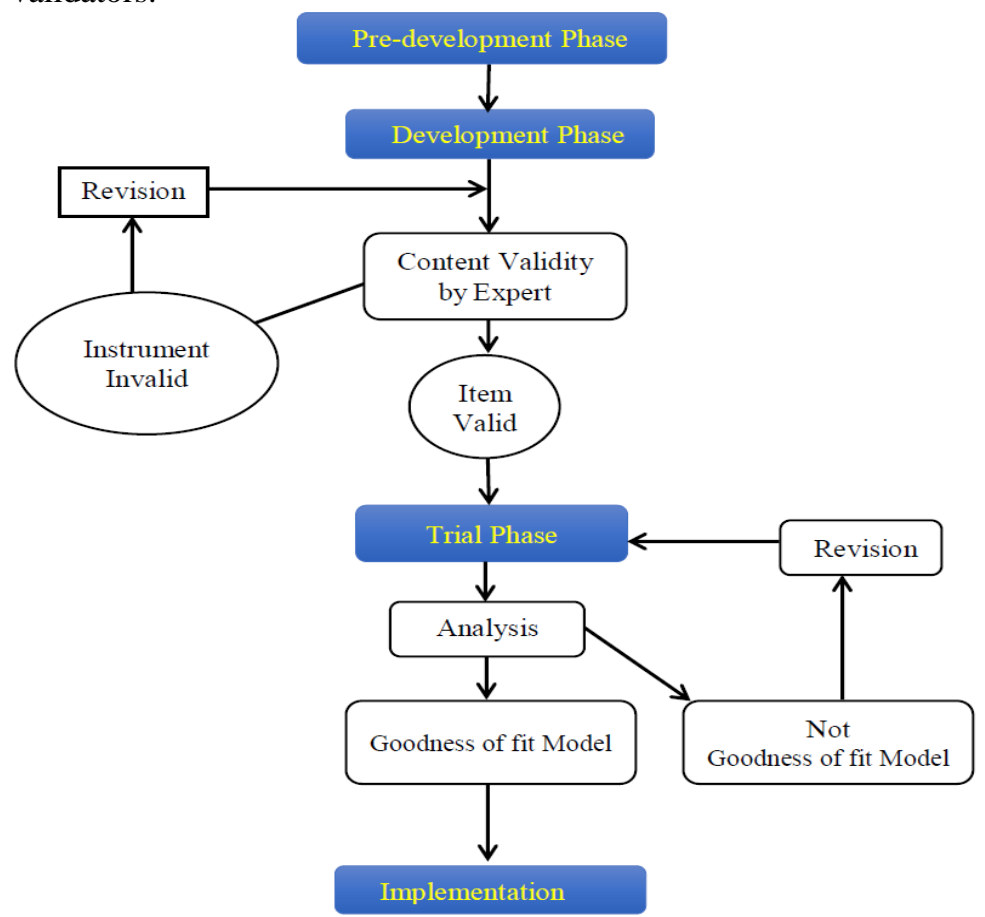

Figure 1

Instrument Development Chart Model

The next step is trial in a limited area that was administered to 505 learners of XI-MIA class in high school (SMA and MA, in Indonesia), which are both public and private schools in Pemalang. The data were tested using three categories of polytomous data. The data were analyzed using three programs, namely the Quest program to verify the suitability of the model and the difficulty level of the item while the Parcale program to obtain information function and Standard Error of Measurement (SEM). The construct validity of the instrument was obtained by applying Confirmatory Factor Analysis using Lisrel program. After obtaining valid instrument items which have a good degree of difficulty (between -2.00 to +2.00 ), the implementation was conducted. The development procedure could be reviewed in Figure 1. 


\section{Data Collection Instruments}

Physics lab assessment is divided into four stages, namely (1) preparation of practicum, (2) practicum performance, (3) practicum results and (4) practicum reporting. Each stage is spelled out into several indicators, so each indicator will be formulated in the form of a statement or command that directs the learners to perform the investigation steps. Each command is supplemented with three categories of polytomous assessment rubric.

The research data were collected in two ways, in the preparation and practicum phases data were collected by direct observation by physics teacher in their respective schools during the physics lab. Meanwhile, at the practicum result stage, the data were collected through the test which was obtained from the observation list during the practicum. This test was a question or command related to the data obtained during the physics lab. In the fourth stage or reporting stage, the data were collected through the assessment of the physics lab report.

\section{Preparation and Implementation Phases}

The preparation phase consists of five indicators while the implementation stage consists of four indicators. These indicators were developed into a command or instruction sentence for learners to do something related to physics practicum. Teachers observed the quality of learners' performance in conducting their teachers' instruction and scored them by using a scale of 1 - 3. Learners who completely could not do the teacher's instruction will get the teacher's assistance and got minimum score that was 1 .

\section{The Result and Reporting Phases}

The results stage consists of eight indicators while the implementation stage consists of four indicators. These indicators were developed into a command or instruction sentence for learners to do something related to the results of the physics lab. What was instructed or directed at these two stages was written on a paper which had been provided. The teacher made corrections to the learners' work using a scale of 1 - 3 .

\section{Participants and sampling technique}

The participants of this study are the learners of Senior High School (SMA) and Madrasah Aliyah (MA) class XI IPA in Pemalang Indonesia, in total 505 students consisting of men and women. This research uses stratified random sampling technique with high school quality, medium quality and low quality category.

\section{The Procedure of Implementation}

In this study, teachers form groups, each group consisting of 2 learners and each group was given a set of tools and practicum materials. One practicum consists of 5 to 7 groups, adjusted for the large number of science classes in each school. The teacher gives an assessment of the four stages using the rubric that has been provided.

Preparation phase. At this stage there are 5 commands that must be done by learners. The teacher observes the learner during the run of the five commands. In the preparation phase, the teacher scores the learner for each indicator according to the performance quality of the learners with 3 categories, score 3: very good; score 2: good and score 1: not good. 
Implementation phase. At this stage there are 4 commands that must be done by learners, the teacher observes the learner during the run of the five commands. In the implementation phase, the teacher scores the learner for each indicator according to the performance quality of the learners with 3 categories, score 3: very good; score 2: good and score 1: not good

Stage results. At this stage there are 8 commands to be done by the learner regarding the analysis of experimental data. Once completed, teachers can begin an assessment of what has been collected. In the Stage results, the teacher scores the learner for each of the indicators presented in the lab results of the learners with 3 categories as score 3: very good; score 2: good and score 1: not good.

Stage of lab report. Learners make a lab report, as specified. Then an assessment of the report consists of 4 indicators. The lab report is then scored by teachers with three categories on each indicator; score 3: very good; score 2: good and score 1: not good. (for more details, see the instrument trailer in the attachment)

\section{Technique of Data Analysis}

The data obtained were analyzed by using three programs, namely Quest program to verify model suitability and difficulty index level, and Parcale program to obtain information function and Standard Error of Measurement (SEM). The data in this research were the data of polytomous of three categories. The validity test of the content was done by the expert and the data were analyzed using Aiken formula. The data analysis technique included several aspects, namely: a) Goodness of fit to PCM, b) validity of item, c) item difficulty level, d) instrument reliability, e) information function and Standard Error of Measurement (SEM).

Goodness of fit to PCM: The fit test on the overall test based on the mean and standard deviation of INFIT MNSQ. If the mean value of INFIT MNSQ approaches 1.00 and the standard deviation is close to 0.00 , then the overall item is fit in the PCM 1 PL model. All of these analyses can be performed with the help of the QUEST program.

Item Validity: An item is considered to be fit, according to Adams \& Khoo (1996), on the model if INFIT MNSQ value is in the range between 0.77 and 1.30 . Items are in good condition or fit to use.

The Reliability of Instrument: Estimation of instrument reliability can be reviewed based on the output of QUEST program analysis for the reliability for item and reliability for testee. According to Mardapi (2012) the instrument is quite good if it has a reliability coefficient or reliability index equal to or greater than 0.70 .

Difficulty Indeces of Item: Estimation of the level of difficulty in the instrument can be performed with the help of the QUEST program. The item is said to be good if the item difficulty index is between -2 to +2 .

Information Function and SEM: Estimation of information function and SEM is performed with the help of parscale program. Based on this information function and SEM, a test or instrument would be likely suitable to be tested to testee with certain capability $(\theta)$ (high, low or moderate). 


\section{FINDINGS AND DISCUSSION}

The product of this development is the instrument of Physics Lab assessment for senior high school level with scoring rubric of scale $1-3$. This physics lab assessment instrument consists of four stages; preparation stage and implementation phase in the form of observation sheet of learners conducted by the teacher during the Physics Lab. The result stage is a test that is generated from the results of observation data during the Physics Lab which is packed in the form of questions that can lead the learners to do something, such as making a graph. The fourth stage is the reporting stage where each learner makes a report of Physics Lab, then an assessment is carried out on a scale of 13 and this applies to all stages.

\section{The Fit of Item of Physics Lab Instrument}

If the mean value of INFIT MNSQ approaches 1.00 and the standard deviation is close to 0.00 , then the overall item is fit in the PCM model.

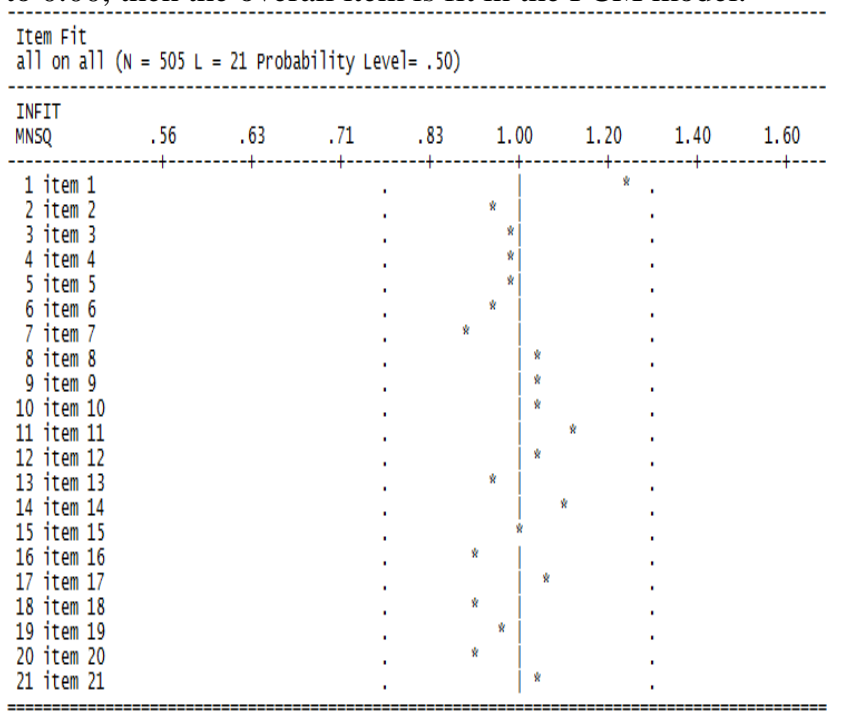

Figure 2

Plot Item Physics Lab

The plot of instrument item for skill competence assessment can be seen in Figure 2. Based on Figure 2 it can be seen that all the items in the skill competence assessment instrument are in the range of 0.77 and 1.30. This shows that all of them are using PCM 1 PL model.

\section{Estimation Results}

Based on the results of the analysis of the expanded test data, the characteristics of the competency assessment instrument for physics lab of class XI were obtained. The 21item estimation results were performed by 505 learners with a probability level of 0.5 and by using polytomous scoring according to PCM $1 \mathrm{PL}$ of the three categories, the results are shown in Table 1. 
Table 1

Estimation of Physics Lab Item Instrument

\begin{tabular}{lc}
\hline Description & Trial \\
\hline Testee Reliability & 0.95 \\
\hline Value of INFIT MNSQ & 0.86 \\
\hline RMSEA & $0,88-1,21$ \\
\hline Mean and Standard Deviation of INFIT MNSQ & $1,01 \pm 0,08$ \\
\hline RMSEA & $-1,15-0,85$ \\
\hline
\end{tabular}

Based on Table 1, it is proved that the INFIT MNSQ value is from 0.88 to 1.21 . The mean and standard deviation values of INFIT MNSQ are $1.00 \pm 0.08$, thus all items fit according to the PCM model. Item difficulty level is between -1.15 to 0.85 , so all items are in good condition, supported by high instrument reliability of 0.95 .

\section{Item Difficulty Level}

An illustration of the difficulty level is given in grading the competency appraisal instruments of physics skills of class XI class. The distribution of item difficulty levels from the four stages and categories can be seen in Table 2.

Table 2

Distribution of items Exchange Rates

\begin{tabular}{|c|c|c|c|c|c|c|}
\hline No & Stages & Indicators & Difficulties & category 1 & category 2 & category 3 \\
\hline \multirow[t]{6}{*}{1} & \multirow{5}{*}{ Preparation } & 1 & -0.08 & -0.49 & -0.11 & 0.52 \\
\hline & & 2 & 0.17 & -0.43 & 0.9 & 0.40 \\
\hline & & 3 & -0.54 & -0.51 & -0.33 & 0.30 \\
\hline & & 4 & -0.08 & -0.19 & -0.31 & 0.42 \\
\hline & & 5 & 0.12 & -0.51 & 0.23 & 0.40 \\
\hline & \multicolumn{2}{|c|}{ Average Difficulty } & 0.08 & & & \\
\hline \multirow[t]{5}{*}{2} & \multirow{4}{*}{$\begin{array}{l}\text { Stage } 2 \\
\text { Implementation }\end{array}$} & 1 & 0.05 & -0.43 & 0.12 & 0.36 \\
\hline & & 2 & 0.06 & -0.48 & 0.16 & 0.38 \\
\hline & & 3 & 0.07 & -0.44 & 0.13 & 0.38 \\
\hline & & 4 & 0.05 & -0.53 & 0.17 & 0.41 \\
\hline & \multicolumn{2}{|c|}{ Average Difficulty } & 0.06 & & & \\
\hline \multirow[t]{9}{*}{3} & Stage 3 & 1 & 0.12 & -0.56 & 0.21 & 0.47 \\
\hline & \multirow[t]{7}{*}{ Results } & 2 & 0.02 & -0.38 & 0.01 & 0.39 \\
\hline & & 3 & -0.12 & -0.44 & -0.12 & 0.44 \\
\hline & & 4 & -0.15 & -0.32 & -0.22 & 0.39 \\
\hline & & 5 & -0.13 & -0.31 & -0.23 & 0.41 \\
\hline & & 6 & 0.67 & 0.39 & -0.23 & 0.51 \\
\hline & & 7 & 0.98 & 0.54 & -0.05 & 0.49 \\
\hline & & 8 & -0.35 & -0.36 & -0.4 & 0.41 \\
\hline & \multicolumn{2}{|c|}{ Average Difficulty } & 0.13 & & & \\
\hline \multirow[t]{5}{*}{4} & & 1 & -0.01 & -0.31 & -0.14 & 0.44 \\
\hline & \multirow{3}{*}{ Reporting } & 2 & 0.08 & -0.52 & 0.14 & 0.46 \\
\hline & & 3 & -0.07 & -0.39 & -0.13 & 0.45 \\
\hline & & 4 & 0.33 & -0.36 & 0.27 & 0.42 \\
\hline & \multicolumn{2}{|c|}{ Average Difficulty } & 0.08 & & & \\
\hline
\end{tabular}

Based on Table 3 it is seen that the second stage, ie the implementation stage has the lowest difficulty level of -0.08 . The next difficulty level is the implementation stage 
(0.06), the next difficulty level is the result stage (0.08). While the most difficult stage is the third stage, the yield stage of 0.13 . Because each stage has a different level of difficulty, the more difficult stage should have a higher weight.

This indicates that inquiry-based physics learning still needs to be improved. Inquirybased activities should be used as a preferred instruction method in preservice teacher education (Tatar \& Nilgün, 2012). For more details, a diagram of the difficulty level of the items of each stage can be made, as shown in Figure 3.

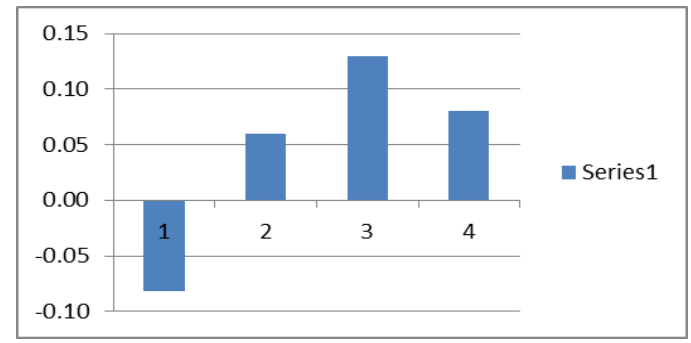

Figure 3

Level of Exchange of Points in Each Stage

Information:

1 : Preparation phase

2 : Implementation phase

3 : Results phase

$4:$ lab report phase

\section{Appropriate ability for developed instruments}

Based on the results of data analysis, the graph of information and SEM function is presented in Figure 5. Figure 5 shows that assessment instrument for the skills provides the ability information between $-1,90$ and +1.90 , the competency appraisal instrument for skills is more appropriately applied to the respondents with the ability $(\theta)$ of -1.90 $\leq \theta \leq+1.90$. Capacity coverage is wide enough; so it is very suitable to be applied to high school learners whose input consists of various economic background, social culture and varying abilities.

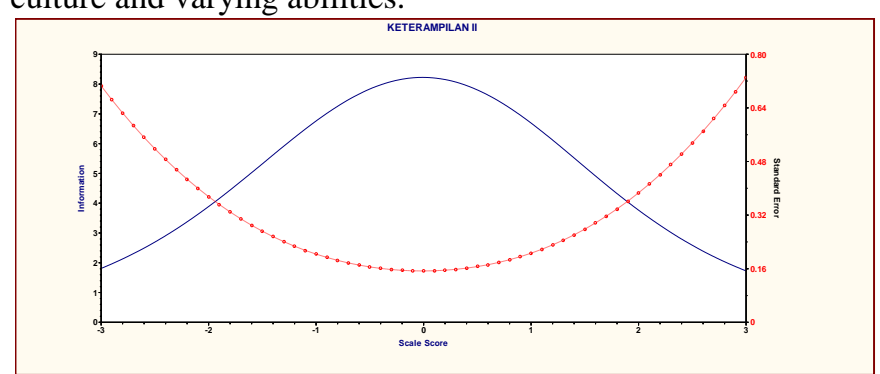

Figure 4

Information Function and Standard Error Measurement Kurve Physics Lab Instrument 


\section{CONCLUSION}

All the items of the draft of the High School physics lab assessment apparatus having a range of difficulty levels between -2.00 and +2.00 means that all of the substance of the instrument is in good category. Instrument assessment of high school Physics Lab has high reliability of 0.95 . Based on the information on function graph and Standard Error of Measurement, instrument of physics high school physics lab, it is appropriate to measure learners with abilities from $-2,6$ to $+1,90$.

Physical lab instrument is a set of physics learning with the method of investigation, on the subject of harmonic motion. This instrument is equipped with scoring and rubric assessment so as to facilitate teachers in implementing physics learning. In addition, this instrument can be used as a reference for physics teacher in developing physics lab appraisal instruments for other language subjects.

Instruments were developed as valid, reliable and suitable to be applied to learners who have medium ability.

Students' critical thinking disposition increased significantly after implementation of performance assessment model in physics laboratory (Emiliannur et al, 2017). Further, it is said that the guided inquiry laboratory experiments developed positive attitudes towards chemistry laboratory and decreased the students' chemistry laboratory anxiety (Ural, 2016).

\section{RECOMMENDATIONS}

Teachers can use the physics lab instrument that has been developed to obtain a fair and accurate assessment result on the matrix spring and mathematical material.

\section{REFERENCES}

American Association of Physics Teachers. (2014). Recommendations for the Undergraduate Physics Laboratory Curriculum, Report prepared by a Sub committee of the AAPT Committee on Laboratories.

Ariani, D., Saptaningrum, E \& Siswanto, J (2016). Scientific Skills Assessment Instrument on Physics Learning Based Inquiry. Journal of Physics Learning, 7(2). 109-117.

Chinn, C. A. (2011). Educational Psychology: Understanding Students' Thinking, Rutgers University.

Corlu, M. A. \& Corlu, M. S. (2012). Scientific Inquiry Based Professional Development Models in Teacher Education. Educational Sciences: Theory \& Practice, 12(1), 514521

Depdikbud. (2017). Assessment Guide for Upper Secondary Education Unit. Directorate General of Primary and Secondary Education Ministry of Education and Culture.

Depdikbud. (2013). Regulation of the Minister of Education and Culture of the Republic of Indonesia Number 66 Year 2013 regarding Education Appraisal Standards. Jakarta. 
Ekawati, E. Y. (2017). A model of scientific attitudes assessment by observation in physics learning based scientific approach: case study of dynamic fluid topic in high school. Journal of Physics: Conference Series. 1-9.

Emiliannur, E., Hamidah, I., Zainul , A. \& Wulan, A.R. (2017). Using Performance Assessment Model in Physics Laboratory to Increase Students' Critical Thinking Disposition. International Conference on Mathematics and Science Education (ICMScE). IOP Conf. Series: Journal of Physics: Conf. Series 895

Feynman, R. P., Leighton, R. B. \& Sunds, M. (1963). The Fyenman Lecturea on Physics. Addison Wesley Publishing Company.

Makgato, M. \& Mji, A. (2006). Factors associated with high school learners' poor performance, a spotlight on mathematics and physical science. South African Journal of Education, 26, 253-266.

Frey, B. \& Allen, J. (2012). Defining Authentic Classroom Assessment. Practical Assessment, Research \& Evaluation, 17(2), 1-18.

Hofstein, A \& Lunetta, V. (2003). The Laboratory in Science Education: Foundations for the Twenty-First Century. Science Education, 88 (1): 28-54.

Mardapi, D. (2012). Development of educational research instruments, Prints 1, Nuha Medika, Yogyakarta.

Mardapi, D. (2008). Technique of preparation of test and non test instrument. Yogyakarta: Mitra Cendekia Press.

Orsmond, P. (2004). Self-and Peer-Assessment: Guidance on Practice in the Biosciences. Teaching Bioscience: Enhancing Learning Series, First published in Great Britain.

K. Havlíček. (2015). Experiments in Physics Education: What do Students Remember?. WDS'15 Proceedings of Contributed Papers - Physics, 144-148.

L, Chasanah, I, Kaniawati \& H, Hernani. (2017). How to Assess Creative Thinking Skill in Making Products of Liquid Pressure?. International Conference on Mathematics and Science Education (ICMScE), Conf. Ser. 895 012164, 1-8

Rochmawati, R \& Wahyuni, S. (2017). Authentic Assessment in Physics Learning Using Physics Chess Game for Senior High School. International Journal of Learning and Teaching, 3(1), $15-18$.

Tatar \& Nilgün (2012) Inquiry-Based Science Laboratories: An Analysis Of Preservice Teachers' Beliefs About Learning Science Through Inquiry And Their Performances. Journal of Baltic Science Education, 11(3), 248-266.

Wenning, C. (2003). Improving Physics Teacher Preparation. Journal Of Physics Teacher Education Online, 1(4), 1-32.

Ural, E. (2016). The Effect of Guided Inquiry Laboratory Experiments on Science Education Students' Chemistry Laboratory Attitudes, Anxiety and Achievement. Journal of Education and Training Studies, 4(4), 217-227. 